\title{
Dinâmica de fermentação ruminal in vitro do pseudofruto de cinco clones de cajueiro ${ }^{1}$
}

\author{
Marcia Mourão Ramos Azevedo², Vânia Rodrigues Vasconcelos ${ }^{3}$, José Carlos Machado Pimentel ${ }^{4}$, \\ Bruno Ítalo Sousa Pinto ${ }^{5}$, José Cardoso de Araújo Neto ${ }^{6}$, Adeline de Andrade Carvalho ${ }^{6}$
}

\author{
${ }^{1}$ Pesquisa financiada pela FINEP/CNPq. \\ 2 Programa de Pós-Graduação em Ciência Animal/UFPI. Bolsista do CNPq. \\ 3 Departamento de Zootecnia/UFPI. \\ ${ }^{4}$ Embrapa Agroindústria Tropical-CNPAT/EMBRAPA. \\ ${ }^{5}$ Curso de Biologia - CCN/UFPI. \\ ${ }^{6}$ Curso de Medicina Veterinária - CCA/UFPI.
}

RESUMO - Avaliou-se a dinâmica de fermentação ruminal dos carboidratos totais (CT) e da fibra em detergente neutro (FDN) do pseudofruto de cinco clones de cajueiro (CP 06, CP 09, CP 76, CP 1001 e BRS 189) pela técnica in vitro semiautomática de produção de gases. As leituras de pressão foram realizadas 3, 6, 9, 12, 15, 21, 27, 33, 39, 48, 60 e 72 horas para determinação da degradação dos carboidratos totais e da FDN, pela quantificação do resíduo após 72 horas de incubação. As curvas de produção cumulativa de gases foram ajustadas utilizando-se os modelos propostos por France e Gompertz para carboidratos totais e fibra em detergente neutro, respectivamente. Na avaliação da degradação dos carboidratos totais, o potencial máximo de produção de gases (Vf) diferiu entre o CP 09 e o BRS 189. O CP 1001 foi o que apresentou menor tempo de colonização. As taxas de fermentação dos CP 09, CP 1001 e CP 06 foram ligeiramente superiores às do CP 76 e dos BRS 189. A taxa de produção de gases apresentou dois picos, às 6 e às 21 horas. O BRS 189 foi o que apresentou menor degradação às 72 horas de fermentação. Na avaliação da fermentação ruminal da FDN, O CP 09 apresentou maior potencial máximo de produção de gases e o CP 06, CP 1001 e BRS 189, maiores taxas de produção de gases. A eficiência microbiana foi maior no CP 09 e a produção cumulativa de gases, no CP 1001. Os pseudofrutos dos clones de cajueiro avaliados têm potencial para uso na alimentação de ruminantes por terem boa qualidade fermentativa.

Palavras-chave: carboidratos totais, degradação, fibra em detergente neutro

\section{In vitro rumen fermentation dynamics of false fruit from five cashew clone trees}

\begin{abstract}
The kinetics of ruminal fermentation of total carbohydrates (TC) and neutral detergent fiber (NDF) of false fruit from five clones of cashew tress: CP 06, CP 09, CP 76, CP 1001, BRS 189 was evaluated through semi-automated in vitro gas production technique. The pressure readings and the volume measurements were accomplished after 3, 6, 9, 12, $15,21,27,33,39,48,60$ and $72 \mathrm{~h}$. For the determination of the TC and NDF degradation, the residue was quantified after $72 \mathrm{~h}$ of incubation. The cumulative gas production curves were adjusted through models proposed by France and Gompertz for TC and NDF, respectively. For TC, difference between CP 09 and BRS 189 was found for potential gas production (Vf). The CP 1001 was the substrate that presented the shortest colonization time. The CP 09, CP 1001 and the CP 06 presented fermentation rates slightly higher in relation to CP 76 and BRS 189. The existence of two peaks was observed in the gas production rate, for 6 and $21 \mathrm{~h}$. The BRS 189 presented lower degradation at $72 \mathrm{~h}$. For the NDF, CP 09 resulted in higher Vf and the CP 06, CP 1001 and o BRS 189 presented the highest gas production rate. The CP 09 presented had higher microbial efficiency. The cumulative gas production was higher for CP 1001. The false fruit of the cashew trees clones evaluated presented potential for use in the feeding of ruminants due to their good quality, from the fermentative point of view.
\end{abstract}

Key Words: degradation, neutral detergent fiber, total carbohydrates

\section{Introdução}

A menor produção das forragens durante o período seco tem sido apontada como um dos fatores que mais contribuem para a baixa produtividade dos rebanhos. A necessidade de alimentos de qualidade no período seco é constante em todos os sistemas de produção de ruminantes.

De acordo com Barros \& Crisóstomo (1995), o cajueiro (Anacardium occidenlale L.) encontra-se disseminado 
em quase todos os países tropicais e sua produção concentra-se na estação seca do ano, período com menor disponibilidade de forragem, tanto quantitativa como qualitativamente (Holanda et al., 1996). O fruto é constituído da castanha (10\%) e do pedúnculo $(90 \%)$, que, após a retirada da castanha, é desperdiçado em mais de $90 \%$ ainda no campo (Holanda et al., 1996). Segundo o IBGE (2005), o Brasil é o terceiro produtor mundial de castanha de caju, com produção de 251.268 toneladas. A Região Nordeste é responsável por $100 \%$ da exploração econômica do cajueiro, que se concentra nos estados do Ceará, Piauí e Rio Grande do Norte (IBGE, 2007).

O sucesso no cultivo do cajueiro nos ecossistemas em que tem sido introduzido depende de sistemas de produção que incluam genótipos adaptados às condições de clima e solo locais. O processo de melhoramento genético realizado no cajueiro-anão precoce no Brasil teve início em 1965 no Campo Experimental de Pacajus (Paiva \& Barros, 2004) e constou da seleção fenotípica individual, seguida do controle anual da produção nas plantas selecionadas. Essa metodologia permitiu o lançamento comercial dos clones CCP 06, CCP 76, CCP 09 e CCP 1001. Posteriormente, novos procedimentos metodológicos possibilitaram a obtenção dos clones EMBRAPA 50, EMBRAPA 51, BRS 189 e BRS 226.

$\mathrm{O}$ processo de melhoramento genético possibilitou a produção de clones, que viabilizou o aumento da produtividade, precocidade e qualidade do produto final.

O potencial de utilização do pseudofruto do cajueiro na alimentação animal tem sido evidenciado na literatura (Dantas Filho et al., 2007; Nunes et al., 2007; Ferreira et al., 2004; Furusho et al., 1997; Holanda et al., 1996), entretanto, estudos sobre o valor nutritivo do pseudofruto de clones de cajueiro visando sua utilização na alimentação de ruminantes ainda são escassos na literatura.

Objetivou-se estimar a dinâmica de fermentação ruminal in vitro dos carboidratos totais e da fibra em detergente neutro do pseudofruto de cinco clones do cajueiro.

\section{Material e Métodos}

Avaliou-se a dinâmica de fermentação ruminal dos carboidratos totais e da FDN do pseudofruto de cinco clones do cajueiro: CP 06, CP 09, CP 76, CP 1001 e BRS 189.

Os pseudofrutos foram obtidos dos jardins clonais da Embrapa Agroindústria Tropical, Estação Experimental de Pacajus, Ceará. Inicialmente, foram submetidos à pré-secagem ao sol por 20 dias para retirada de parte da umidade e levados à estufa com ventilação forçada a $55^{\circ} \mathrm{C}$ durante 72 horas. Após a pré-secagem, amostras foram submetidas à trituração grosseira e, posteriormente, foram trituradas em moinho com peneira de porosidade de $1 \mathrm{~mm}$ e armazenadas em recipientes hermeticamente fechados.

Para isolamento da FDN, 2,5 g da amostra e $250 \mathrm{~mL}$ da solução detergente neutro, preparada segundo Silva \& Queiroz (2002), foram colocados em um reboiler e aquecidos a $125^{\circ} \mathrm{C}$ por 1 hora (Van Soest et al., 1991; Pell \& Schofield, 1993). Em seguida, o conteúdo foi transferido para um cadinho filtrante revestido com tecido de náilon. O material retido foi lavado por aproximadamente 20 minutos com água destilada quente e $200 \mathrm{~mL}$ de acetona, visando remover todo o detergente da amostra, e, em seguida, foi seco em estufa com ventilação forçada a $55^{\circ} \mathrm{C}$ por 72 horas. Esse procedimento foi repetido várias vezes até a obtenção de quantidade suficiente desta fração para a condução dos ensaios, conforme descrito por Noguera et al. (2005).

A composição química das amostras foi avaliada segundo métodos descritos por Silva \& Queiroz (2002) para determinação da composição em matéria seca (MS), matéria mineral (MM), proteína bruta (PB), fibra em detergente neutro (FDN), fibra em detergente ácido (FDA) e nitrogênio insolúvel em detergente neutro (NIDN). Os conteúdos de fenóis totais (FT) e taninos totais (TT) foram analisados pelo método Folin-Ciocalteu e os de taninos condensados (TC), pelo método butanol- $\mathrm{HCl}$ (Makkar, 2000).

Para avaliação da dinâmica de fermentação ruminal, preparou-se o meio de cultura a partir de solução de micro e macrominerais, de solução tampão, de solução redutora e de solução indicadora, conforme descrito por Maurício et al. (2001). O conteúdo ruminal foi coletado de um bovino mestiço fistulado no rúmen mantido com dieta composta de capim-elefante roxo, feno de leucena e concentrado à base de grão de milho, farelo de soja e mistura mineral, formulada para atender as exigências nutricionais de animais dessa categoria, segundo o NRC (2001). A ração foi oferecida duas vezes ao dia, às 8 e às $16 \mathrm{~h}$. $\mathrm{O}$ animal passou por um período de 14 dias de adaptação à dieta e, durante o período experimental, foi mantido em baia individual com livre acesso à água. O inóculo foi preparado após coleta das frações sólida e líquida do conteúdo ruminal, às $7 \mathrm{~h} 30$, que foram homogeneizadas em liquidificador na proporção 1:1 durante 5 segundos, filtrando-se o material resultante em quatro camadas de tecido de algodão. Até o momento de sua utilização, o inóculo obtido foi saturado com $\mathrm{CO}_{2}$, para manutenção da anaerobiose, e mantido a $39^{\circ} \mathrm{C}$.

As amostras foram incubadas conforme descrito por Maurício et al. (2001): em frascos de vidro com capacidade 
de $160 \mathrm{~mL}$, foram adicionados $1 \mathrm{~g}$ da amostra, $90 \mathrm{~mL}$ do meio nutritivo e $\mathrm{CO}_{2}$. Em seguida, os frascos foram levados a estufa com circulação forçada de ar a $39^{\circ} \mathrm{C}$ por aproximadamente 1 hora. Após esse período, os frascos foram adicionados de $10 \mathrm{~mL}$ do inóculo ruminal e vedados com rolhas de borracha e lacres de alumínio. Após a colocação dos lacres, os gases gerados no interior de cada frasco foram eliminados e levados novamente à estufa para manutenção da temperatura. Como controles foram utilizados frascos contendo apenas o inóculo ruminal e o meio nutritivo.

As leituras de pressão foram realizadas 3, 6, 9, 12, 15, $21,27,33,39,48,60$ e 72 horas de incubação, com auxílio de um transdutor de pressão conectado a uma válvula de duas saídas. Para quantificação da degradação dos carboidratos totais e da FDN, após a última leitura, colocaram-se os frascos em imersão no gelo para cessar a fermentação e posteriormente transferiu-se o conteúdo dos frascos para cadinhos filtrantes $\mathrm{n}^{\circ} 2$ utilizando-se água destilada para retirada do resíduo remanescente no interior dos frascos e transferência final para os cadinhos filtrantes. Em seguida, os cadinhos filtrantes foram levados à estufa a $105^{\circ} \mathrm{C}$ por 24 horas e resfriados em dessecador e pesados.

As curvas de produção cumulativa de gases dos carboidratos totais foram ajustadas utilizando-se o modelo proposto por France et al. (1993):

$$
V_{T}=V_{F}\{1-\exp [-b(t-L)-c(\sqrt{t}-\sqrt{L})]\}
$$

em que: $\mathrm{V}_{\mathrm{T}}=$ produção cumulativa de gases $(\mathrm{mL})$ no tempo $\mathrm{t} ; \mathrm{V}_{\mathrm{F}}=$ potencial máximo de produção de gases (assíntota); $\mathrm{L}=$ tempo de colonização; $\mathrm{t}=$ tempo de incubação; $\mathrm{b}\left(\mathrm{h}^{-1}\right)$ e c $\left(\mathrm{h}^{-0,5}\right)=$ taxas fracionais constantes.

A taxa de fermentação $(\mu)$ e o tempo necessário para atingir a metade do potencial de produção de gases ( $\mathrm{T}$ 1/2) foram obtidos pelo modelo proposto por France et al. (1993), no qual $\mu$ é determinada por:

$$
\mu=b+c /(2 \sqrt{t})
$$

e

$$
T \frac{1}{2}=\left[\frac{-c / 2 \pm \sqrt{\left(c^{2} / 4+b(b L+c \sqrt{L}+\operatorname{In} 2)\right)}}{b}\right]^{2} .
$$

As curvas de produção cumulativa de gases da FDN foram ajustadas empregando-se o modelo Gompertz, proposto por Lavrencic et al. (1997): $V_{T}=V_{F} \times \exp (-C \times \exp (-A \times t))$, em que: $\mathrm{V}_{\mathrm{T}}=$ produção cumulativa de gases no tempo $t ; \mathrm{V}_{\mathrm{F}}=$ potencial máximo de produção de gases; $\mathrm{C}=$ taxa constante de produção de gases do material potencialmente degradável; $\mathrm{A}=$ fator constante de eficiência microbiana; $t=$ tempo de incubação.

As curvas de ajuste e as estimativas dos parâmetros de interesse biológico foram realizadas pelo processo interativo de Marquardt, com auxílio do procedimento para modelos não-lineares (PROC NLIN) do SAS (1999). Os parâmetros estimados pelos modelos foram comparados em delineamento em blocos casualizados com cinco clones (tratamentos) e quatro repetições utilizando-se o Generalized Linear Model Procedures (PROC GLM) do SAS (1999) e as médias dos tratamentos e suas respectivas interações, utilizando-se o teste de Student-Newman-Keuls (SNK), pelo procedimento PROC GLM do SAS (1999).

\section{Resultados e Discussão}

Os percentuais de PB apresentaram variação de até $41,8 \%$ entre os clones e estão acima do intervalo de 6 a $8 \%$ recomendado por Van Soest (1994) para efetiva fermentação microbiana ruminal. Os valores de FDN e FDA também apresentaram variação elevada entre os clones. Os teores de fenóis totais e taninos totais foram maiores para o clone CP 06 e os de taninos condensados para o clone BRS 189 (Tabela 1).

Os clones CP 09 e BRS 189 diferiram $(\mathrm{P}<0,05)$ quanto ao potencial máximo de produção de gases (Vf) (Tabela 2). O BRS 189 foi o que apresentou maior teor de FDN e tanino condensado, o que pode ter influenciado a disponibilidade dos carboidratos totais para a fermentação.

O CP 1001 foi o que apresentou menor $(\mathrm{P}<0,05)$ tempo de colonização, o que pode estar associado ao maior teor de $\mathrm{PB}$ e ao menor teor de tanino condensado. Segundo Noguera et al. (2005), os processos de adesão e colonização do substrato pelos microrganismos são facilitados quando há disponibilidade de substrato de rápida fermentação. De acordo com Tomich et al. (2003), além da disponibilidade de substratos prontamente fermentáveis, as características físicas e químicas da parede celular da amostra também facilitam a colonização microbiana. Considerando que a retenção média do alimento no rúmen é de 48 horas, seria desejável que a maior parte dos nutrientes digestíveis fosse fermentada nesse intervalo.

A degradação in vitro da matéria seca do BRS 189 foi menor $(\mathrm{P}>0,05)$ que a do CP 06, CP 76, CP 1001 e CP 09, fato provavelmente relacionado ao maior teor de FDN. Na avaliação da degradação ruminal de alfafa, aveia-preta, leucena e guandu, Pires et al. (2006) também verificaram 
Tabela 1 - Composição química (com base na MS) do pseudofruto de cinco clones de cajueiro (Anacardium occidentale L.)

\begin{tabular}{|c|c|c|c|c|c|}
\hline Composição & \multicolumn{5}{|c|}{ Clone } \\
\hline Matéria seca $(\%)$ & 92,80 & 88,20 & 86,90 & 88,90 & 88,00 \\
\hline Fibra em detergente neutro (\%) & 37,47 & 35,50 & 34,80 & 39,86 & 43,74 \\
\hline Fibra em detergente ácido (\%) & 31,69 & 26,04 & 26,87 & 25,04 & 24,06 \\
\hline Matéria mineral $(\%)$ & 3,70 & 4,47 & 3,74 & 4,36 & 2,56 \\
\hline Tanino total $^{1}$ & 16,03 & 11,88 & 10,23 & 8,72 & 12,24 \\
\hline Tanino condensado ${ }^{2}$ & 1,10 & 1,10 & 1,50 & 0,80 & 2,20 \\
\hline $\begin{array}{l}\text { Nitrogênio insolúvel em detergente } \\
\text { neutro(\% do nitrogênio total) }\end{array}$ & 68,15 & 66,00 & 80,14 & 38,13 & 58,68 \\
\hline
\end{tabular}

${ }^{1}$ Fenol total e Tanino total - valores expressos em equivalente-grama de ácido tânico/kg de MS

2 Tanino condensado - valores expressos em equivalente-grama de leucocianidina $/ \mathrm{kg}$ de MS

Tabela 2 - Cinética da fermentação ruminal dos carboidratos totais do pseudofruto de cinco clones de cajueiro e degradação da matéria seca (DMS) em 72 horas de incubação

\begin{tabular}{|c|c|c|c|c|c|c|}
\hline \multirow[t]{2}{*}{ Parâmetro ${ }^{1}$} & \multicolumn{5}{|c|}{ Clone } & \multirow[t]{2}{*}{$\mathrm{epd}^{2}$} \\
\hline & СР 06 & СР 76 & CP 1001 & СР 09 & BRS 189 & \\
\hline $\mathrm{Vf}\left(\mathrm{ml} \cdot \mathrm{g}^{-1} \mathrm{MS}\right)$ & $162,787 \mathrm{ab}$ & $167,662 \mathrm{ab}$ & $169,935 \mathrm{ab}$ & $183,724 \mathrm{a}$ & $148,869 b$ & 5,607 \\
\hline $\mathrm{b}\left(\mathrm{h}^{-1}\right)$ & $0,05622 \mathrm{a}$ & $0,04733 \mathrm{a}$ & $0,05979 a$ & $0,06555 \mathrm{a}$ & $0,04345 \mathrm{a}$ & 0,012 \\
\hline c $\left(h^{-1 / 2}\right)$ & $-0,06428 \mathrm{a}$ & $0,04857 \mathrm{a}$ & $-0,06817 \mathrm{a}$ & $-0,02128 \mathrm{a}$ & $0,05721 \mathrm{a}$ & 0,053 \\
\hline L (h) & $2,2072 \mathrm{a}$ & $2,4787 a$ & $1,6664 b$ & $2,5371 \mathrm{a}$ & $2,2641 \mathrm{a}$ & 0,081 \\
\hline REL 1 & 0,920 & 0,933 & 0,930 & 0,950 & 0,930 & - \\
\hline REL 2 & 0,964 & 0,961 & 0,970 & 0,980 & 0,962 & - \\
\hline $\mathrm{T}^{1} 1 / 2 \quad(\mathrm{~h})$ & $8,621 \mathrm{a}$ & $8,362 \mathrm{a}$ & $8,257 \mathrm{a}$ & $7,702 \mathrm{a}$ & $8,072 \mathrm{a}$ & 0,012 \\
\hline DMS $(\mathrm{g} / \mathrm{kg})$ & $613,90 a$ & $563,53 \mathrm{a}$ & $519,00 \mathrm{a}$ & $600,78 \mathrm{a}$ & $379,80 \mathrm{~b}$ & 25,483 \\
\hline
\end{tabular}

${ }^{1}$ Vf: potencial máximo de produção de gases; b e c: são taxas fracionais constantes; L: "lag phase"; REL1: relação entre as produções de gases após 48 e 72 horas; REL2: relação entre as produções de gases após 72 horas e Vf; (T 1/2): tempo necessário para se atingir a metade do potencial de produção de gases.

2 epd: erro-padrão da diferença entre médias.

Médias seguidas de letras iguais na mesma linha não diferem $(\mathrm{P}>0,05)$ entre si pelo teste SNK.

diferença na degradação final (72 horas) da matéria seca e relataram que essa diferença pode ter sido influenciada pela quantidade de parede celular nas forrageiras, pois o teor de FDN variou, apresentando menor degradação nas forragens com maior teor de FDN. Essas diferenças na degradação também podem ser atribuídas ao maior teor de tanino, pois esta substância protege a proteína e a celulose da degradação ruminal (Van Soest, 1994). Pereira Filho et al. (2005), avaliando a correlação entre a concentração de tanino e a degradação ruminal da matéria seca e proteína bruta do feno de jurema-preta, observaram que o aumento da concentração de tanino influencia negativamente a degradação da matéria seca e mais intensamente a degradação da proteína bruta.

A relação entre as produções de gases após 48 e 72 horas (Tabela 2) auxilia na comparação dos alimentos, pois representa proporcionalmente quanto da produção total de gases no período avaliado ocorreu até 48 horas de incubação. Quanto mais próximo possível de 1 o valor dessa relação, melhor a qualidade fermentativa do alimento. Por outro lado, a relação entre as produções de gases após 72 horas e o potencial máximo de produção de gases permite estimar se o ensaio de produção de gases foi longo o suficiente para exprimir o potencial fermentativo do alimento e/ou se o modelo ajustou-se coerentemente aos dados (Bueno et al., 2005). Os valores obtidos para a relação entre as produções de gases após 48 e 72 horas e para a relação entre as produções de gases após 72 horas e o potencial máximo de produção de gases foram elevados para todos os clones, o que indica que a avaliação permitiu, ao menos aparentemente, boa interpretação dos perfis de degradação. Bueno et al. (2005) avaliaram nove alimentos comumente utilizados na dieta de ruminantes: feno de alfafa, Brachiaria decumbens em duas idades de corte (28 e 56 dias), palha de trigo, cinco diferentes amostras de azevém-perene e obtiveram valores inferiores aos deste trabalho para relação entre as produções de gases após 48 e 72 horas $(0,890$; 0,$674 ; 0,673 ; 0,683 ; 0,748 ; 0,840 ; 0,864 ; 0,864$ e 0,848 , respectivamente) e para a relação entre as produções de gases após 72 horas e o potencial máximo de produção de 
gases $(0,995 ; 0,940 ; 0,934 ; 0,882 ; 0,956 ; 0,986 ; 0,991 ; 0,989$; 0,987 , respectivamente). Nozella et al. (2006) estudaram cinco forrageiras do Nordeste e também obtiveram valores inferiores para esses parâmetros.

O tempo necessário para atingir a metade do potencial de produção de gases não diferiu $(\mathrm{P}>0,05)$ entre os clones e foi bem inferior ao estimado por Maurício et al. (1999), entre 14,9 e 16,0 horas, e Nozella et al. (2006), entre 19,4 e 35,2 horas, na avaliação de outros alimentos.

A taxa de fermentação $(\mu)$, um parâmetro que depende do tempo de incubação de cada alimento, não diferiu $(\mathrm{P}>0,05)$ entre os clones avaliados. O CP 09, CP 1001 e o CP 06 apresentaram taxas de fermentação ligeiramente superiores em relação ao CP 76 e BRS 189 (Figura 1). As maiores taxas ocorreram no tempo inicial de fermentação, confirmando relatos de Bueno (2002) de que a maior concentração de carboidratos não-fibrosos resulta em maior $\mu$ e que, com o transcorrer do tempo, esses componentes tornam-se escassos e as fontes de energia restantes (FDN) são fermentadas com menor velocidade.

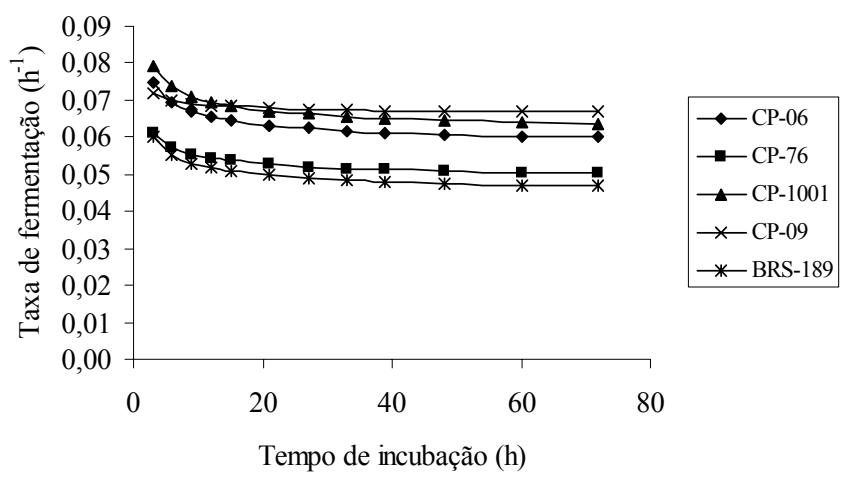

Figura 1 - Taxa de fermentação $(\mu)$ dos carboidratos totais do pseudofruto de cinco clones de cajueiro (Anacardium occidentale L.)

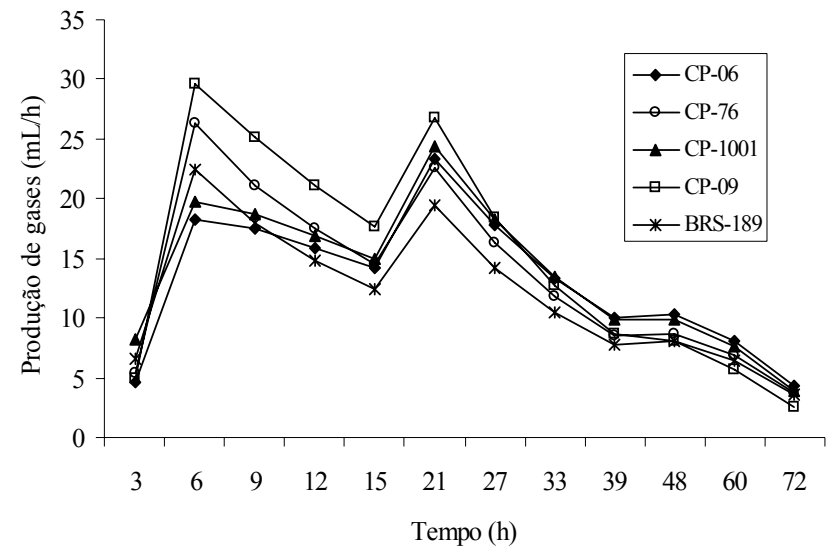

Figura 2 - Produção de gases dos carboidratos totais do pseudofruto de cinco clones de cajueiro (Anacardium occidentale L.).
Segundo Blümmel \& Ørskov (1993) e Maurício et al. (2003), os parâmetros estimados pelo modelo de France et al. (1993), principalmente a taxa de fermentação $(\mu)$, proporcionam maiores coeficientes de correlação com o consumo em comparação aos obtidos em experimentos de digestibilidade aparente. Dessa forma, o CP 09, CP 1001 e o CP 06 verificados neste experimento poderiam acarretar maiores consumos, em relação ao CP 76 e BRS 189, por apresentarem maior potencial nutritivo. De acordo com Pires et al. (2006), o consumo de alimentos está correlacionado negativamente à FDN, ou seja, quanto maior o teor de FDN, menor a degradabilidade e maior o tempo de permanência da forragem no rúmen, o que limita a ingestão de alimento.

As curvas das taxas de produção de gases $(\mathrm{mL} / \mathrm{h})$ dos clones nos tempos de fermentação (Figura 2) apresentaram três picos: às 6,21 e 48 horas de incubação.

A maior taxa de produção de gases dos clones CP 09, CP 76 e BRS 189 ocorreu no primeiro pico e a dos clones CP 06 e CP 1001, no segundo pico. Esse comportamento foi similar ao observado por Maurício et al. (2003) em silagens de quatro híbridos de sorgo, cujos picos nas taxas de produção de gases ocorreram às $8 \mathrm{~h}$ e entre $16 \mathrm{e} 24 \mathrm{~h}$, fato atribuído à fermentação dos carboidratos solúveis na fase inicial e à fermentação dos carboidratos fibrosos posteriormente. O terceiro pico, registrado às 48 horas de incubação, está relacionado à reciclagem microbiana. Entretanto, Váradyová et al. (2005), em pesquisa com feno de pastagem, palha de trigo, celulose amorfo e grão de cevada, observaram apenas um pico na taxa de produção de gases, aproximadamente às 3 horas, tanto com inóculo de fluido ruminal como de fezes frescas.

O CP 09 apresentou maior produção cumulativa de gases (mL/g CT), seguido pelo CP 76, CP 1001, CP 06 e BRS 189, que apresentaram os maiores teores de FDN e de tanino condensado (Figura 3).

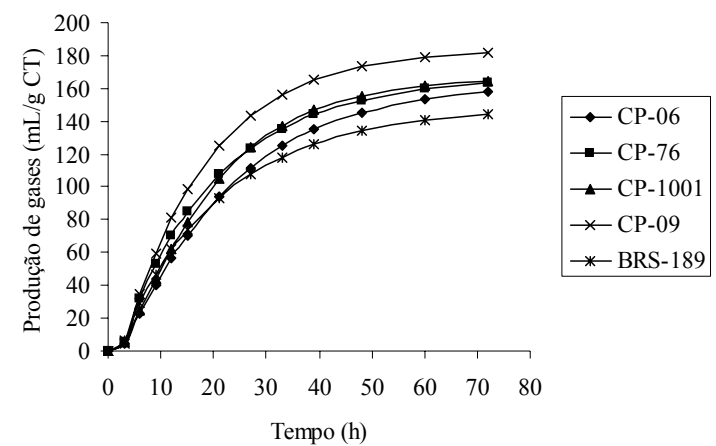

Figura 3 - Curvas de produção cumulativa de gases dos carboidratos totais do pseudofruto de cinco clones de cajueiro (Anacardium occidentale L.). 
A energia utilizada pelos microrganismos nas primeiras horas de incubação é proveniente, quase que totalmente, da fermentação dos carboidratos não-fibrosos (Azevêdo et al., 2003), o que condiz com a maior velocidade de produção de gases nos tempos iniciais. Segundo Van Soest (1994), a parede celular é constituída de polímeros heterogêneos e pode possuir frações de fácil e difícil degradação microbiana, resultando em diferentes produções de gases. O BRS 189 foi o que apresentou menor volume após 30 horas.

As curvas de produção cumulativa de gases refletiram na degradação do material, confirmando resultados descritos porCruzetal.(2006). Entretanto, Nogueira etal.(2006), comparando substratos com diferentes teores de carboidratos solúveis, obtiveram maior degradação para os carboidratos com menor produção de gases e atribuíram essa menor produção de gases ao fato de que a fermentação de carboidratos solúveis proporciona maior produção de propionato e, conseqüentemente, menor produção de gases, pois a formação de propionato envolve a captura do hidrogênio $\left(\mathrm{H}_{2}\right)$ e não implica formação de dióxido de carbono $\left(\mathrm{CO}_{2}\right)$.

Todos os parâmetros de qualidade de cinética de fermentação ruminal diferiram $(\mathrm{P}<0,05)$ entre os clones. $\mathrm{O}$ CP 09 apresentou maior potencial de produção de gases e o CP 06, a menor capacidade de fermentação e o menor volume de gases, possivelmente em razão do maior teor de FDA e fenóis totais (Tabela 3 ).

OCP 06, CP1001 e BRS 189 apresentaram maiores taxas de produção de gases (c), diferindo $(\mathrm{P}<0,05)$ dos demais. A eficiência microbiana, descrita como crescimento microbiano, diferiu $(\mathrm{P}<0,05)$ entre os clones e foi maior para o CP 09 , o que indica maior eficiência de aproveitamento da fração fibrosa do alimento pelos microrganismos ruminais. Noguera et al. (2005) também encontraram diferenças nesse parâmetro ao estudarem a fração fibrosa de diversos alimentos, cujos valores variaram de 3,97 a 5,50 mL/g de FDN. Houve diferença
$(\mathrm{P}<0,05)$ na degradação in vitro da FDN após 72 horas de incubação do CP 1001, CP 76 e BRS 189 para o CP 06 e CP 09. Essas variações obtidas na degradação da FDN, em sua maioria, estão relacionadas ao teor e à constituição da fibra presente no alimento (Pires et al., 2006). Entretanto, Noguera et al. (2005) ressaltaram que a cinética de degradação da FDN em forragens com fatores antinutricionais como os taninos, pode ser alterada, uma vez que esses fatores podem ser removidos durante o processo de obtenção da FDN.

A maior produção cumulativa de gases ( $\mathrm{mL} / \mathrm{g}$ de $\mathrm{FDN}$ ) foi observada para o CP 1001, seguido pelo BRS 189, CP 06, CP 76 e CP 09 (Figura 4).

$\mathrm{O}$ volume de gases produzido até 72 horas foi baixo para todos os clones e variou entre 59 e $80 \mathrm{~mL} / \mathrm{g}$ de FDN. Noguera et al. (2005) também obtiveram menores volumes de produção de gases para a fração FDN em comparação aos da MS e atribuíram esse resultado ao fato de que, durante a degradação da FDN, não ocorre o efeito associativo e aditivo das frações solúveis e insolúveis.

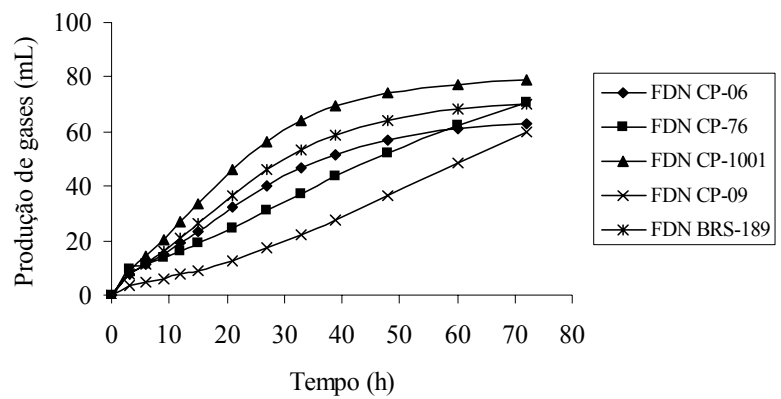

Figura 4 - Curvas de produção cumulativa de gases da FDN do pseudofruto de cinco clones de cajueiro (Anacardium occidentale L.).

Tabela 3 - Cinética de fermentação ruminal da FDN do pseudofruto de cinco clones de cajueiro (Anacardium occidentale L.) e degradação da FDN (DFDN) em 72 horas de incubação

\begin{tabular}{|c|c|c|c|c|c|c|}
\hline \multirow[t]{2}{*}{ Parâmetro ${ }^{1}$} & \multicolumn{5}{|c|}{ Clone } & \multirow[t]{2}{*}{ epd ${ }^{2}$} \\
\hline & СР 06 & CP 76 & СР 1001 & СР 09 & BRS 189 & \\
\hline $\mathrm{Vf}\left(\mathrm{ml} \cdot \mathrm{g}^{-1} \mathrm{MS}\right)$ & $64,854 \mathrm{c}$ & $93,276 b$ & $79,690 \mathrm{bc}$ & $113,435 \mathrm{a}$ & $71,310 \mathrm{bc}$ & 3,958 \\
\hline$c\left(h^{-1}\right)$ & $0,06168 \mathrm{a}$ & $0,03064 b$ & $0,07661 \mathrm{a}$ & $0,02409 \mathrm{~b}$ & $0,06757 \mathrm{a}$ & 0,0053 \\
\hline A & $2,545 \mathrm{~b}$ & $2,524 b$ & $2,732 b$ & $3,627 \mathrm{a}$ & $2,732 b$ & 0,161 \\
\hline DFDN (g/kg) & $138,19 b$ & $164,79 \mathrm{ab}$ & $202,45 \mathrm{a}$ & $108,67 \mathrm{~b}$ & $159,75 \mathrm{ab}$ & 13,372 \\
\hline
\end{tabular}

${ }^{1}$ Vf: potencial máximo de produção de gases; c: taxa constante de produção de gases do material potencialmente degradável; A: fator constante de eficiência microbiana.

2 epd: erro-padrão da diferença entre médias.

Médias seguidas de letras iguais na mesma linha não diferem entre si pelo teste SNK $(\mathrm{P}>0,05)$ 


\section{Conclusões}

Os pseudofrutos dos clones de cajueiro CP 06, CP 09, CP 76, CP 1001 e BRS 189 apresentam potencial para uso na alimentação de ruminantes por serem de boa qualidade fermentativa.

\section{Agradecimentos}

Ao CNPq/FINEP, pela bolsa de estudo concedida ao primeiro autor e pelo apoio financeiro, necessários à condução da pesquisa.

À Embrapa Agroindústria Tropical, pelo fornecimento das amostras.

\section{Literatura Citada}

AZEVÊDO, J.A.G.; PEREIRA, J.C.; QUEIROZ, A.C. et al. Composição químico-bromatológica, fracionamento de carboidratos e cinética da degradação in vitro da fibra de três variedades de cana-de-açúcar (Saccharum spp.). Revista Brasileira de Zootecnia, v.32, n.6, p.1443-1453, 2003.

BARROS, L.M.; CRISÓSTOMO, J.R. Melhoramento genético do cajueiro. In: ARAÚJO, J.P.P.; SILVA, V.V. (Eds.) Cajucultura: modernas técnicas de produção. Fortaleza: EMBRAPA - CNPAT, 1995. p.73-93.

BLÜMMEL, M.; ØRSKOV, E.R. Comparison of in vitro gas production and naylon degradability of roughage in predicting feed intake in cattle. Animal Feed Science and Technology, v.40, p.109-119, 1993.

BUENO, I.C.S. Cinética digestiva e síntese microbiana ruminal em ovinos alimentados com fenos de três qualidades distintas. 2002. 97f. Tese (Doutorado em Ciência) - Centro de Energia Nuclear na Agricultura, Piracicaba, 2002.

BUENO, I.C.S.; CABRAL FILHO, S.L.S.; GOBBO, S.P. et al. Influence of inoculum source in a gas production method. Animal Feed Science and Technology, v.123, p.95-105, 2005.

CRUZ, P.G.; FIGUEIREDO, M.P.; COSTA, S.S. et al. Avaliação nutricional de cinco variedades de cana-de-açúcar (Saccharum spp.) pela técnica in vitro de semi-automática de produção de gases. In: REUNIÃO ANUAL DA SOCIEDADE BRASILEIRA DE ZootecniA, 43., 2006, João Pessoa. Anais... João Pessoa: Sociedade Brasileira de Zootecnia/Gmosis, [2006]. (CD-ROM)

DANTAS FILHO, L.A.; LOPES, J.B.; VASCONCELOS, V.R. et al. Inclusão de polpa de caju desidratada na alimentação de ovinos: desempenho, digestibilidade e balanço de nitrogênio. Revista Brasileira de Zootecnia, v.36, n.1, p. 147-154, 2007.

FERREIRA, A.C.H.; NEIVA, J.N.M.; RODRIGUEZ, N.M. et al. Valor nutritivo das silagens de capim-elefante com diferentes níveis de subprodutos da indústria do suco de caju. Revista Brasileira de Zootecnia, v.33 n.6, p.1380-1385, 2004.

FRANCE, J.; DHANOA, M.S.; THEODOROU, M.K. et al. A model to interpret gas accumulation profiles associated with in vitro degradation of ruminant feeds. Journal of Theoretical Biology, v.163, p.99-111, 1993.

FURUSHO, I.F.; PÉREZ, J.R.O.; LIMA, G.F.C. et al. Desempenho de cordeiros Santa Inês, terminados em confinamento, com dieta contendo pedúnculo do caju. In: REUNIÃO ANUAL DA SOCIEDADE BRASILEIRA DE ZOOTECNIA, 34., 1997, Juiz de Fora. Anais... Juiz de Fora: Sociedade Brasileira de Zootecnia, 1997. p.385-387.
HOLANDA, J.S.; FURUSHO, I.F.; LIMA, G.F.C. et al. Perspectiva de uso do pedúnculo de caju na alimentação animal. In: SIMPÓSIO NORDESTINO DE ALIMENTAÇÃO DE RUMinantes, 6., 1996, Natal. Anais... Natal: Sociedade Nordestina de Produção Animal, 1996. p.155-161.

INSTITUTO BRASILEIRO DE GEOGRAFIA E ESTATÍSTICA IBGE. [2005]. Anuário Estatístico do Brasil. Disponível em: $<$ http://www.sidra.ibge.gov.br/bda/tabela/listabl.asp?c=1618> Acesso em: 20/5/2007.

LAVRENCIC, A.; STEFANON, B.; SUSMEL, P. An evaluation of the Gompertz model in degradability studies of forage chemical components. Animal Science, v.64, p.423-431, 1997.

MAKKAR, H.P.S. Quantification of tannins in tree foliage. Vienna: FAO; IAEA, 2000. p.1-10. (Laboratory Manual).

MAURÍCIO, R.M.; MOULD, F.L.; DHANOA, M.S. et al. A semiautomated in vitro gas production technique for ruminant feedstuff evaluation. Animal Feed Science and Technology, v.79, p.321-330, 1999

MAURÍCIO, R.M.; OWEN, E.; MOULD, F.L. et al. Comparison of bovine rumen liquor and bovine faeces as inoculum for an in vitro gas production technique for evaluating forages. Animal Feed Science and Technology, v.89, p.33-48, 2001.

MAURÍCIO, R.M.; PEREIRA, L.G.R.; GONÇALVES, L.C. et al. Potencial da técnica in vitro semi-automática de produção de gases para avaliação de silagens de sorgo (Sorghum bicolor (L.) Moench). Revista Brasileira de Zootecnia, v.32, n.4, p.1013-1020, 2003.

NATIONAL RESEARCH COUNCIL - NRC. Nutrient requirements of dairy cattle. 7.ed. Washington, D.C.: National Academy Press, 2001. 381p.

NOGUEIRA, U.T.; MAURÍCIO, R.M.; GONÇALVES, L.C. Comparação de substratos com diferentes quantidades de carboidratos solúveis utilizando a técnica in vitro semi-automática de produção de gases. Arquivo Brasileiro de Medicina Veterinária e Zootecnia, v.58, n.4, p.633-641, 2006.

NOGUERA, R.R.; SALIBA, E.O.; GONÇALVES, L.C. et al. [2005]. Utilização da técnica de produção de gás para determinar a cinética de fermentação dos carboidratos estruturais e não estruturais em sorgo para forragem. Livestock Research for Rural Development, v.17, n.5, 2005. Disponível em: $<$ http://www.cipav.org.co//rrd//rrd17/5/nogu17053.htm > Acesso em: 18/7/2007.

NOZELLA, E.F.; CABRAL FILHO, S.L.S.; BUENO, I.C.S. et al Caracterização de forrageiras do Nordeste utilizando a técnica de produção de gases, composição química e quantificação de taninos. 1. Plantas do estado da Bahia. In: REUNIÃO ANUAL DA SOCIEDADE BRASILEIRA DE ZOOTECNIA, 43., 2006, João Pessoa. Anais... João Pessoa: Sociedade Brasileira de Zootecnia/Gmosis, [2006]. (CD-ROM).

NUNES, H.; ZANINE, A.M.; MACHADO, T.M.M. et al. Alimentos alternativos na dieta dos ovinos. Archivos Latinoamericanos de Producción Animal, v.15, n.4, p.141-151, 2007.

PAIVA, J.R.; BARROS, L.M. Clones de cajueiro: obtenção, características e perspectivas. Fortaleza: EMBRAPA-CNPAT, 2004. 26p. (Documentos, 82).

PELL, A.N.; SCHOFIELD, P. Computerized monitoring of gas production to measure forage digestion in vitro. Journal of Dairy Science, v.76, n.9, p.1063-1073, 1993.

PEREIRA FILHO, J.M.; VIEIRA, E.L.; KAMALAK, A. et al. [2005]. Correlação entre o teor de tanino e a degradabilidade ruminal da matéria seca e proteína bruta do feno de juremapreta (Mimosa tenuiflora Wild) tratada com hidróxido de sódio. Livestock Research for Rural Development, v.17, n.8, 2005. Disponível em: <http://www.cipav.org.co//rrd//rrd17/8/ pere 17091.htm>. Acesso em: 12/2/2008.

PIRES, A.J.V.; REIS, R.A.; CARVALHO, G.G.P. et al. Degradabilidade ruminal da matéria seca, da fração fibrosa e da proteína bruta de forrageiras. Pesquisa Agropecuária Brasileira, v.41, n.4, p.643-648, 2006. 
SILVA, D.J.; QUEIROZ, A.C. Análise de alimentos: métodos químicos e biológicos. 3.ed. Viçosa, MG: Editora UFV, 2002. $235 \mathrm{p}$.

STATISTICAL ANALYSIS SYSTEM - SAS. User's guide: statistics. Version 8.0. Cary: 1999. (CD-ROM).

TOMICH, T.R.; GONÇALVES, L.C.; MAURICIO, R.M. et al. Composição bromatológica e cinética de fermentação ruminal de híbridos de sorgo com capim-sudão. Arquivo Brasileiro de Medicina Veterinária e Zootecnia, v.55, n.6, p.747-755, 2003.
Van SOEST, P.J. Nutritional ecology of the ruminant. 2.ed. Ithaca: Cornell University Press, 1994. 476p.

Van SOEST, P.J.; ROBERTSON, J.B.; LEWIS, B.A. Methods for dietary fiber, neutral detergent fiber, and nonstarch polyssacarides in relation to animal nutrition. Journal of Dairy Science, v.74, n.10, p.3583-3597, 1991.

VÁRADYOVÁ, Z.; BARAN, M.; ZELENAK, I. Comparison of two in vitro fermentation gas production methods using both rumen flid and faecal inoculum from sheep. Animal Feed Science and Technology, v.123-124, p.81-94, 2005. 